\title{
Establishing relationship between fusion zone hardness and grain size of gas tungsten constricted arc welded thin sheets of titanium alloy
}

\author{
V. Vaithiyanathan ${ }^{1}$ (D) V. Balasubramanian ${ }^{1} \cdot$ S. Malarvizhi ${ }^{1} \cdot$ Vijay $^{\text {Petley }}{ }^{2} \cdot$ Shweta Verma $^{2}$
}

Received: 16 May 2019 / Accepted: 4 December 2019/ Published online: 16 December 2019

(c) Springer Nature Switzerland AG 2019

\begin{abstract}
Ti-6Al-4V alloys are perfectly suited for fan compressor blade material in advanced aero engine components due to outstanding resistance to corrosion and specific strength was high in both room temperature and elevated temperature. For autogeneous welding of thin sheets of Ti-6Al-4V alloy, the gas tungsten constricted arc welding (GTCAW) was established to be beneficial than the gas tungsten arc welding process. The performance of welded joints depends on the fusion zone grain size (FZG) and fusion zone hardness (FZH), which need to be suitably optimized and controlled to attain advantageous mechanical characteristics of the joint. Hence, in this research study, efforts were taken to develop empirical relationships for predicting the FZH and FZG incorporating very important GTCAW parameters. Parameter optimization was performed using response surface methodology. Additionally, the influence of GTCAW parameters on FZG and FZH was analyzed. From the results, it is inferred that the inter-pulse frequency has better influence on FZG and FZH compared to other parameters.
\end{abstract}

Keywords Arc constriction · Ti-6Al-4V alloy · Inter-pulse frequency · Hardness · Grain size

\section{Introduction}

Ti-6Al-4V alloy which comes under the classification of a- $\beta$ titanium ( $\mathrm{Ti}$ ) alloys has many applications aircraft manufacturing, chemical and biomedical industries due to its exceptional characteristics of high strength to density ratio, admirable resistance to corrosion resistance and high temperature withstanding capabilities [1-3]. Weldability of Ti-6Al-4V alloy is good compared to other Ti alloys so that this alloy is being welded for the fabrication of aeroengine components such as compressor blades, engine shrouds, airframes etc. Ti-6Al-4V alloy is an allotropic material in which $\mathrm{Al}$ and $\mathrm{V}$ acts as $\alpha$ and $\beta$ stabilizers respectively. It can be strengthened by various heat treatment and strain hardening processes, in particular by solutionizing with subsequent quenching [4-6]. Moreover, this alloy is very sensitive to thermal cycles during welding, results in catastrophic variations in the microstructure $[7,8]$. Electron beam welding (EBW) and laser beam welding (LBW) are considered as a perfect joining technique for Ti-6Al-4V alloys due to the specific advantages such as high depth of penetration, lesser welding defects and narrower HAZ and FZ compared to GTAW [9-12]. However, EBW process has some limitations such as requirement of vacuum environment and hazard of harmful emission of X-rays [13-15].

New techniques were developed in recent years to eliminate these limitations and most of them were derived from the basic GTAW technique which is highly economical compared to other techniques. One of the very significant derivatives of GTAW used in this investigation was Gas Tungsten Constricted Arc Welding (GTCAW) [16]. GTCAW works at a very high frequency

$\triangle$ V.Vaithiyanathan, vaithimfg@gmail.com; V. Balasubramanian, visvabalu@yahoo.com; S. Malarvizhi, jeejoo@rediffmail.com; Vijay Petley, petleyvijay@gmail.com; Shweta Verma, shweta@gtre.drdo.in | 'Department of Manufacturing Engineering, Centre for Materials Joining and Research (CEMAJOR), Annamalai University, Annamalai Nagar (P.O), Chidambaram, Tamil Nadu 608002, India. ${ }^{2}$ Materials Group (MTG), Gas Turbine Research Establishment (GTRE), Bengaluru 560093, India. 
Fig. 1 Schematic diagram of variants of GTAW used in this investigation
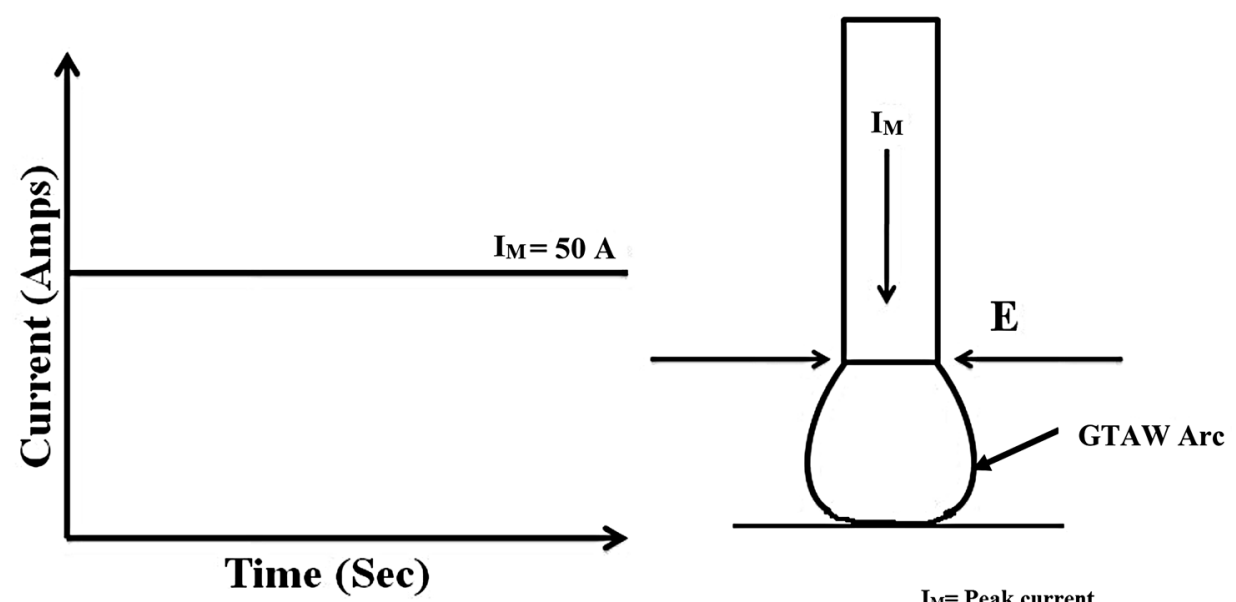

Gas Tungsten Arc Welding (GTAW)

(a)

$I_{M}=$ Peak current $I_{P}=$ Inter-pulse current $I_{F}=$ Inter-pulse frequency $\mathrm{S}=$ Welding speed E= Magnetic field

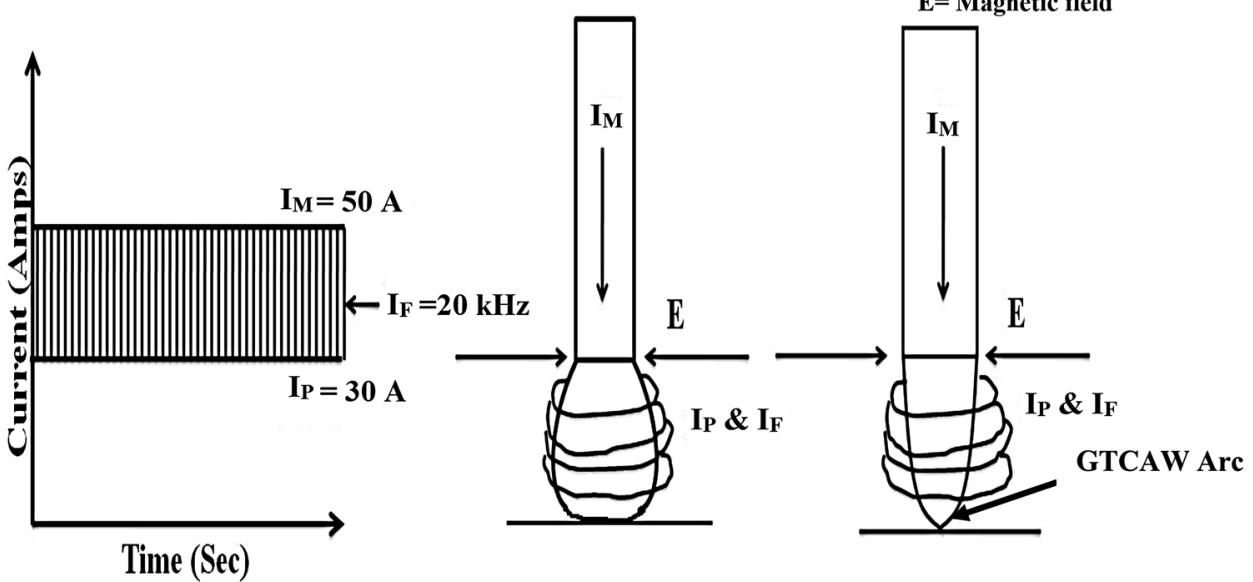

Gas Tungsten Constricted Arc Welding (GTCAW)

(b)

(20 kHz) which is able to generate constricted arc by magnetic constriction with a columnar shape like plasma arc (Fig. 1). The arc constriction leads to narrow HAZ and FZ compared to conventional GTAW process $[17,18]$.

Many optimization techniques were employed to determine the fusion zone (FZ) characteristics by the establishment of analytical models. Response surface methodology (RSM) was widely used for these kind of welding problems [19-21]. Few researchers [22, 23] studied about the impact of pulsed current influence on bead geometry on GTA welding parameters as well as Ti-6Al-4V alloy's mechanical properties.

However, an available information in literature pertaining to GTCAW process parameters and fusion zone characteristics of titanium alloy joints is very scant. Most of the researchers have considered peak current, arc frequency, and welding speed as the input welding parameters but there is no systematic study reported
Table 1 Chemical composition (wt\%) of base alloy

\begin{tabular}{llllll}
\hline Si & C & Fe & V & Al & Ti \\
\hline 0.02 & 0.02 & 0.27 & 3.7 & 6.1 & Bal
\end{tabular}

Table 2 Mechanical properties of base alloy

\begin{tabular}{llll}
\hline $\begin{array}{l}0.2 \% \text { Yield } \\
\text { strength (MPa) }\end{array}$ & $\begin{array}{l}\text { Tensile } \\
\text { strength (MPa) }\end{array}$ & $\begin{array}{l}\text { Elongation } \\
(25 \mathrm{~mm} \text { gauge } \\
\text { length) }(\%)\end{array}$ & $\begin{array}{l}\text { Micro hardness } \\
\left(\mathrm{HV}_{0.2}\right)\end{array}$ \\
\hline 977 & 1010 & 15 & 375 \\
\hline
\end{tabular}

involving "delta current or inter-pulse current and delta frequency or inter-pulse frequency" (important input welding parameters influencing the $F Z G$ and $F Z H$ ). Hence this research work is emphasis on the optimization of essential GTCAW parameters to achieve minimum FZG and maximum FZH employing RSM. 


\section{Experimental}

Ti-6Al-4V alloy sheets were cut into blanks $(150 \mathrm{~mm} \times 75 \mathrm{~mm} \times 1.2 \mathrm{~mm}$ ) for conducting welding experiments. Tables 1 and 2 shows base material chemical composition and mechanical properties.

\subsection{Finding the working limits of the parameters}

The quality of the joints was investigated throughout the trail runs with a combination of different process parameters. Figure 2 obviously highlights the issues come upon during the preliminary runs. By selecting suitable process parameters to overcome the issues to obtain defect free and quality joints.

The independently governable GTCAW parameters influence the grain size and hardness were resolved they are: peak current $\left(I_{M}\right)$, inter-pulse current $\left(I_{P}\right)$, inter-pulse frequency $\left(I_{F}\right)$, and welding speed $(S)$. When detailing the working limits of the process parameters, +2 are coded as upper limits and -2 as lower limits. The in-between coded values were considered from the below relationship [24].

$\left.Z_{i}=2\left[2 Z-\left(Z_{\max }+Z_{\min }\right)\right] /\left(Z_{\max }-Z_{\min }\right)\right]$ where $Z_{i}$ is the required coded value of variable $Z ; Z$ is any value of the variable from $Z_{\text {min }}$ to $Z_{\text {max }} ; Z_{\text {min }}$ is the minimum value of the variable and $Z_{\max }$ is the maximum value of the variable (Table 3 ).

With help of central composite design (CCD) principle, an experimental design matrix was constructed (Table 4). As a result, 30 runs comprised of 16 factorial points, 8 star points and 6 center points. All the 30 runs are experimented and their actual responses were recorded. Analysing and interpolating the recorded responses yielded the relationship effects of the parameters on the FZG and FZH in linear, quadratic and two-way interaction models. All the experiments were carried out employing an Inter-pulse TIG welding machine capable of producing constricted arc.

Metallographic specimens were collected from each joint using wire cut machining and the cross-section face of the specimens were polished using fine emery papers. The acetone-cleaned metallograhically polished specimens were etched using oxalic reagent to expose the $F Z$ microstructure displayed in Fig. 3.

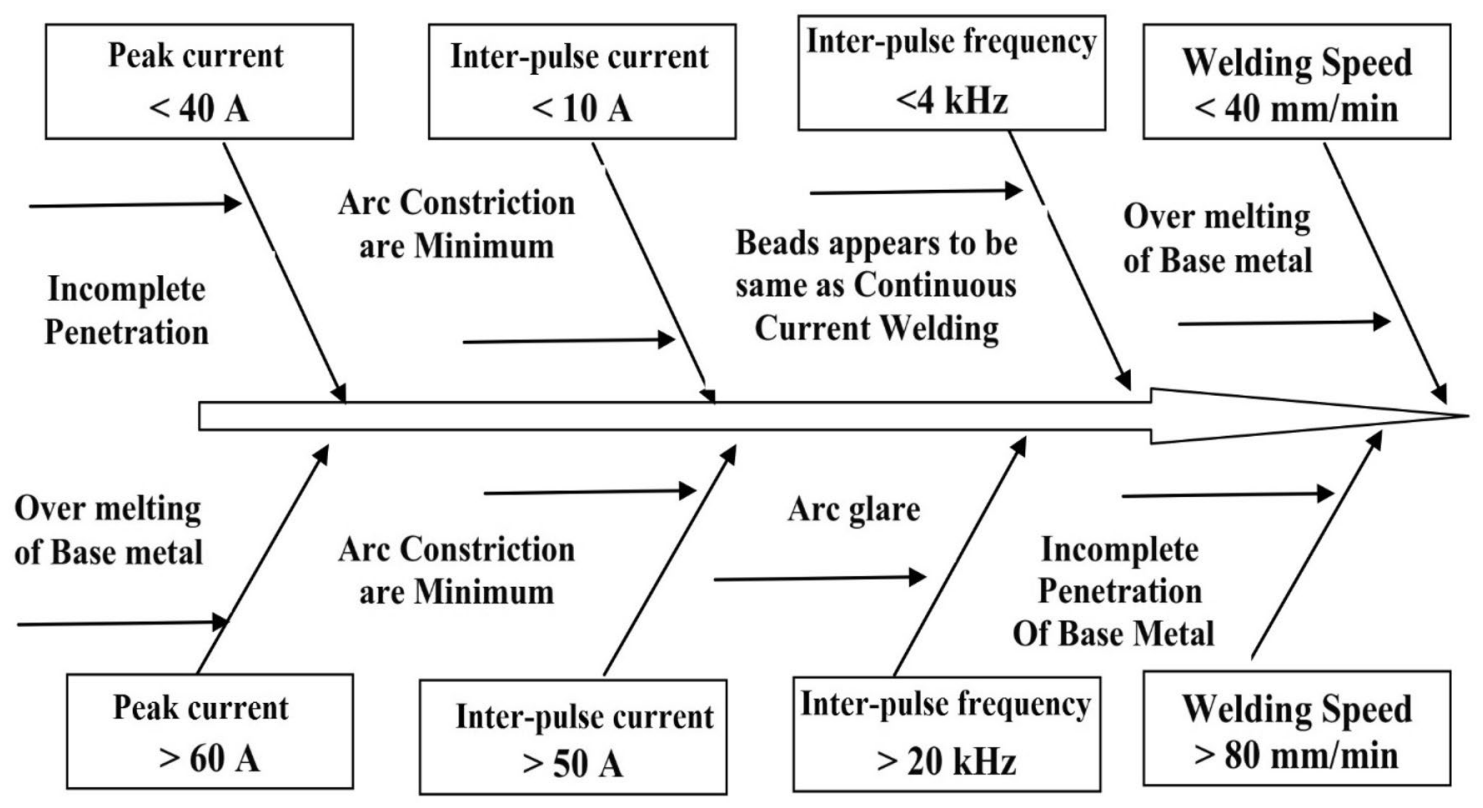

Fig. 2 Cause and effect diagram used for selection of process parameters for optimization

Table 3 Feasible GTCAW process parameters and their levels

\begin{tabular}{llllrrrrr}
\hline No. & Parameter & Notations & Unit & -2 & -1 & 0 & +1 & +2 \\
\hline 1. & Peak current & $\mathrm{I}_{\mathrm{M}}$ & $\mathrm{A}$ & 40 & 45 & 50 & 55 & 60 \\
2. & Inter-pulse current & $\mathrm{I}_{\mathrm{P}}$ & $\mathrm{A}$ & 10 & 20 & 30 & 40 & 50 \\
3. & Inter-pulse frequency & $\mathrm{I}_{\mathrm{F}}$ & $\mathrm{kHz}$ & 4 & 8 & 12 & 16 & 20 \\
4. & Welding speed & $\mathrm{S}$ & $\mathrm{mm} / \mathrm{min}$ & 40 & 50 & 60 & 70 & 80 \\
\hline
\end{tabular}


Table 4 Design matrix and experimental results

\begin{tabular}{|c|c|c|c|c|c|c|c|c|c|c|}
\hline Expt. no. & $I_{M}$ & $I_{P}$ & $I_{F}$ & $S$ & $I_{M}$ & $I_{p}$ & $\mathrm{I}_{\mathrm{F}}$ & $S$ & $\begin{array}{l}\text { Fusion zone } \\
\text { hardness }(\mathrm{Hv})\end{array}$ & $\begin{array}{l}\text { Fusion zone } \\
\text { grain size }(\mu \mathrm{m})\end{array}$ \\
\hline 1 & -1 & -1 & -1 & -1 & 45 & 20 & 8 & 50 & 395 & 334 \\
\hline 2 & 1 & -1 & -1 & -1 & 55 & 20 & 8 & 50 & 382 & 375 \\
\hline 3 & -1 & 1 & -1 & -1 & 45 & 40 & 8 & 50 & 415 & 315 \\
\hline 4 & 1 & 1 & -1 & -1 & 55 & 40 & 8 & 50 & 393 & 342 \\
\hline 5 & -1 & -1 & 1 & -1 & 45 & 20 & 16 & 50 & 421 & 307 \\
\hline 6 & 1 & -1 & 1 & -1 & 55 & 20 & 16 & 50 & 410 & 349 \\
\hline 7 & -1 & 1 & 1 & -1 & 45 & 40 & 16 & 50 & 425 & 305 \\
\hline 8 & 1 & 1 & 1 & -1 & 55 & 40 & 16 & 50 & 400 & 346 \\
\hline 9 & -1 & -1 & -1 & 1 & 45 & 20 & 8 & 70 & 372 & 396 \\
\hline 10 & 1 & -1 & -1 & 1 & 55 & 20 & 8 & 70 & 375 & 401 \\
\hline 11 & -1 & 1 & -1 & 1 & 45 & 40 & 8 & 70 & 385 & 362 \\
\hline 12 & 1 & 1 & -1 & 1 & 55 & 40 & 8 & 70 & 389 & 368 \\
\hline 13 & -1 & -1 & 1 & 1 & 45 & 20 & 16 & 70 & 407 & 325 \\
\hline 14 & 1 & -1 & 1 & 1 & 55 & 20 & 16 & 70 & 396 & 345 \\
\hline 15 & -1 & 1 & 1 & 1 & 45 & 40 & 16 & 70 & 418 & 323 \\
\hline 16 & 1 & 1 & 1 & 1 & 55 & 40 & 16 & 70 & 399 & 343 \\
\hline 17 & -2 & 0 & 0 & 0 & 40 & 30 & 12 & 60 & 425 & 320 \\
\hline 18 & 2 & 0 & 0 & 0 & 60 & 30 & 12 & 60 & 386 & 391 \\
\hline 19 & 0 & -2 & 0 & 0 & 50 & 10 & 12 & 60 & 380 & 380 \\
\hline 20 & 0 & 2 & 0 & 0 & 50 & 50 & 12 & 60 & 404 & 345 \\
\hline 21 & 0 & 0 & -2 & 0 & 50 & 30 & 4 & 60 & 381 & 365 \\
\hline 22 & 0 & 0 & 2 & 0 & 50 & 30 & 20 & 60 & 421 & 311 \\
\hline 23 & 0 & 0 & 0 & -2 & 50 & 30 & 12 & 40 & 410 & 320 \\
\hline 24 & 0 & 0 & 0 & 2 & 50 & 30 & 12 & 80 & 400 & 368 \\
\hline 25 & 0 & 0 & 0 & 0 & 50 & 30 & 12 & 60 & 429 & 263 \\
\hline 26 & 0 & 0 & 0 & 0 & 50 & 30 & 12 & 60 & 434 & 258 \\
\hline 27 & 0 & 0 & 0 & 0 & 50 & 30 & 12 & 60 & 435 & 257 \\
\hline 28 & 0 & 0 & 0 & 0 & 50 & 30 & 12 & 60 & 430 & 255 \\
\hline 29 & 0 & 0 & 0 & 0 & 50 & 30 & 12 & 60 & 435 & 258 \\
\hline 30 & 0 & 0 & 0 & 0 & 50 & 30 & 12 & 60 & 439 & 261 \\
\hline
\end{tabular}

\subsection{Development of empirical relationship}

FZG and FZH is a function of GTCAW parameters such as peak current $\left(I_{M}\right)$, inter-pulse current $\left(I_{p}\right)$, inter-pulse frequency $\left(\mathrm{I}_{\mathrm{F}}\right)$ and welding speed $(\mathrm{S})$ and hence, it can be stated as

$Y=f\left(\mathbf{I}_{M}, I_{P}, I_{F}, S\right)$

$$
\begin{aligned}
Y= & C_{0}+C_{1} I_{M}+C_{2} I_{P}+C_{3} I_{F}+C_{4} S+C_{11} I_{M}^{2}+C_{22} I_{P}^{2} \\
& +C_{33} I_{F}^{2}+C_{44} S^{2}+C_{12} I_{M} I_{P}+C_{13} I_{M} I_{F} \\
& +C_{14} I_{M} S+C_{23} I_{P} S+C_{24} I_{F} S
\end{aligned}
$$

where $C_{0}$ is the mean of response and $C_{1}, C_{2}, \ldots, C_{4}, C_{11}$, $C_{13, \ldots}, C_{34}$ are the coefficients that is based on the interaction and individual effects of parameters. Table 5 shows the calculated coefficients values from DESIGN EXPERT 9.0 software [25].

The empirical relationships to predict FZG and FZH were developed incorporating the values of coefficients. The developed empirical relationships are given below:

Fusion zone hardness $(\mathrm{FZH})=\left\{433.67-7.17\left(\mathrm{I}_{\mathrm{M}}\right)+4.75\right.$ $\left(I_{P}\right)+10.42\left(I_{F}\right)-5.00(S)-1.88\left(I_{M} I_{P}\right)-2.38\left(I_{M} I_{F}\right)+3.00$ $\left(I_{M} S\right)-3.13\left(I_{P} I_{F}\right)+1.00\left(I_{P} S\right)+1.75\left(I_{F} S\right)-7.38$ $\left.\left(I_{M}^{2}\right)-10.75\left(I_{p}^{2}\right)-8.50\left(I_{F}^{2}\right)-7.50\left(S^{2}\right)\right\} \mathrm{Hv}$

Fusion zone grain size $(F Z G)=\{258.67+14.33$ $\left(I_{M}\right)-8.25\left(I_{P}\right)-14.92\left(I_{F}\right)+11.92(S)-0.87\left(I_{M} I_{P}\right)+2.75$ $\left(I_{M} I_{F}\right)-6.25\left(I_{M} S\right)+6.88\left(I_{P} I_{F}\right)-0.87\left(I_{P} S\right)-8.25$ $\left.\left(I_{F} S\right)+23.54\left(I_{M}^{2}\right)+25.29\left(I_{P}^{2}\right)+19.17\left(I_{F}^{2}\right)+20.67\left(S^{2}\right)\right\} \mu m$. 


\begin{tabular}{|c|c|c|c|}
\hline \multirow{2}{*}{ Expt.No } & \multirow{2}{*}{ Parameters } & \multicolumn{2}{|c|}{$\begin{array}{l}\text { Optical Micrograph of Fusion Zone } \\
\end{array}$} \\
\hline & & Top Surface & Cross-Section \\
\hline 2 & $\begin{array}{l}\mathbf{I}_{M}=55 \mathrm{~A} \\
I_{\mathrm{P}}=20 \mathrm{~A} \\
\mathbf{I}_{\mathrm{F}}=8 \mathrm{kHz} \\
S=50 \mathrm{~mm} / \mathrm{min}\end{array}$ & & \\
\hline 4 & $\begin{array}{l}I_{M}=55 \mathrm{~A} \\
I_{P}=40 \mathrm{~A} \\
I_{F}=8 \mathrm{kHz} \\
S=50 \mathrm{~mm} / \mathrm{min}\end{array}$ & & \\
\hline 6 & $\begin{array}{l}I_{M}=55 \mathrm{~A} \\
I_{\mathrm{P}}=20 \mathrm{~A} \\
I_{\mathrm{F}}=16 \mathrm{kHz} \\
S=50 \mathrm{~mm} / \mathrm{min}\end{array}$ & & \\
\hline 12 & $\begin{array}{l}I_{M}=55 \mathrm{~A} \\
I_{\mathrm{P}}=40 \mathrm{~A} \\
I_{\mathrm{F}}=8 \mathrm{kHz} \\
S=70 \mathrm{~mm} / \mathrm{min}\end{array}$ & & \\
\hline 17 & $\begin{array}{l}I_{M}=40 \mathrm{~A} \\
I_{\mathrm{P}}=30 \mathrm{~A} \\
I_{\mathrm{F}}=12 \mathrm{kHz} \\
S=60 \mathrm{~mm} / \mathrm{min}\end{array}$ & & \\
\hline 25 & $\begin{array}{l}I_{M}=50 \mathrm{~A} \\
I_{\mathrm{P}}=30 \mathrm{~A} \\
I_{\mathrm{F}}=12 \mathrm{kHz} \\
S=60 \mathrm{~mm} / \mathrm{min}\end{array}$ & & \\
\hline
\end{tabular}

Fig. 3 Micrograph of the fusion zone profiles 
Table 5 Co-efficient and their estimated factors

\begin{tabular}{lrr}
\hline Coefficient & \multicolumn{1}{l}{ FZH } & \multicolumn{1}{l}{ FZG } \\
\hline Intercept & 433.67 & 258.67 \\
$\mathrm{I}_{M}$ & -7.17 & 14.33 \\
$\mathrm{I}_{P}$ & 4.75 & -8.25 \\
$\mathrm{I}_{F}$ & 10.42 & -14.92 \\
$\mathrm{~S}$ & -5.00 & 11.92 \\
$\mathrm{I}_{M} \mathrm{I}_{P}$ & -1.88 & -0.87 \\
$\mathrm{I}_{M} \mathrm{I}_{F}$ & -2.38 & 2.75 \\
$\mathrm{I}_{M} S$ & 3.00 & -6.25 \\
$\mathrm{I}_{P} \mathrm{I}_{F}$ & -3.13 & 6.88 \\
$\mathrm{I}_{P} S$ & 1.00 & -0.87 \\
$\mathrm{I}_{F} S$ & 1.75 & -8.25 \\
$\mathrm{I}_{M}^{2}$ & -7.38 & 23.54 \\
$\mathrm{I}_{P}^{2}$ & -10.75 & 25.29 \\
$\mathrm{I}_{F}^{2}$ & -8.50 & 19.17 \\
$S^{2}$ & -7.50 & 20.67 \\
\hline
\end{tabular}

\subsection{Checking adequacy of the developed relationships}

The competence of the derived empirical relationships for determining the FZH and FZG of the GTCAW joints was confirmed by analysis of variance (ANOVA) method. According to this method, the calculated Fratio has to be less than the standard Fratio for the model to be satisfactory at $95 \%$ confidence level. The sum of squares, degrees of freedom and $F$ value of the developed models and their interactions are represented in the Table 5.

The Model is found to be significant as the $F$ value of the model is less than the 0.0001 . This indicates that probability of occurrence of this much of larger F-value induced by noise is not more than $0.01 \%$. The model terms which have $p$ value less than 0.05 are considered as significant in the ANOVA tests. Thus the model terms namely $I_{M}, I_{p r}$ $S, I_{M} S, I_{P} I_{F}, I_{M}^{2} I_{P}^{2}, I_{F}^{2}, S^{2}$ are found significant. In the ANOVA table, the lack of fit generally indicates the error in the model and it is very less (2.55) compared to the significant model terms. Thus lack of fit is insignificant. The " $\mathrm{r}^{2}$ " values which are termed as Coefficient of determination is calculated for both actual experiment and the developed

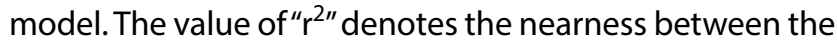
predicted and experimental results. The adj. $\mathrm{r}^{2}$ of 0.9323 is relatively close to the pred. $r^{2}$ of 0.8230 . From the observations made on the ANOVA Tables 6 and 7, it is confirmed that the developed model and the empirical relationships are satisfactory. To validate the values predicted with the help of empirical relationship, three experiments were conducted and their results are presented in Table 8 . The predicted and experimental values have small admissible difference of error.

\subsection{Relationship between fusion zone hardness and grain size}

Figure 4 shows correlated graph of experimentally measured FZG and FZH values that is represented in Table 4. The entire points are allied by a best adequate straight line and the governing equation are given by

$\mathrm{FZH}(\mathrm{Hv})=[547.77-0.42903(\mathrm{FZG}), \mu \mathrm{m}]$

The above equation represents the best adequate straight line as negative sign in the slope and this also suggested that the FZH was inversely proportional influence with
Table 6 ANOVA test results for fusion zone hardness

\begin{tabular}{llrlrll}
\hline Source & Sum of squares & $D f$ & Mean squares & F value & \multicolumn{2}{l}{ p Value prob $>F$} \\
\hline Model & $56,397.8$ & 14 & 4028.41 & 168.123 & $<0.0001$ & Significant \\
$I_{M}$ & 4930.67 & 1 & 4930.67 & 205.778 & $<0.0001$ & \\
$I_{P}$ & 1633.5 & 1 & 1633.5 & 68.173 & $<0.0001$ & \\
$I_{F}$ & 5340.17 & 1 & 5340.17 & 222.868 & $<0.0001$ & \\
$S$ & 3408.17 & 1 & 3408.17 & 142.237 & $<0.0001$ & \\
$I_{M} I_{P}$ & 12.25 & 1 & 12.25 & 0.51125 & 0.4856 & \\
$I_{M} I_{F}$ & 121 & 1 & 121 & 5.04985 & 0.0401 & \\
$I_{M} S$ & 625 & 1 & 625 & 26.0839 & 0.0001 & \\
$I_{P} I_{F}$ & 756.25 & 1 & 756.25 & 31.5616 & $<0.0001$ & \\
$I_{P} S$ & 12.25 & 1 & 12.25 & 0.51125 & 0.4856 & \\
$I_{F} S$ & 1089 & 1 & 1089 & 45.4486 & $<0.0001$ & \\
$I_{M}^{2}$ & $15,201.2$ & 1 & $15,201.2$ & 634.411 & $<0.0001$ & \\
$I_{P}^{2}$ & $17,545.2$ & 1 & $17,545.2$ & 732.236 & $<0.0001$ & \\
$I_{F}^{2}$ & $10,076.2$ & 1 & $10,076.2$ & 420.523 & $<0.0001$ & \\
$S^{2}$ & 11,715 & 1 & 11,715 & 488.919 & $<0.0001$ & \\
Lack of Fit & 318.083 & 10 & 31.8083 & 3.84778 & 0.0750 & Not significant \\
\hline
\end{tabular}


Table 7 ANOVA test results for fusion zone grain size

\begin{tabular}{llrlrrr}
\hline Source & Sum of squares & Df & Mean squares & F value & $\begin{array}{l}p \text { Value } \\
\text { Prob }>\mathrm{F}\end{array}$ & \\
\hline Model & $11,314.1$ & 14 & 808.152 & 29.5066 & $<0.0001$ & Significant \\
$\mathrm{I}_{\mathrm{M}}$ & 1232.67 & 1 & 1232.67 & 45.0061 & $<0.0001$ & \\
$\mathrm{I}_{\mathrm{P}}$ & 541.5 & 1 & 541.5 & 19.7708 & 0.0005 & \\
$\mathrm{I}_{\mathrm{F}}$ & 2604.17 & 1 & 2604.17 & 95.0811 & $<0.0001$ & \\
$\mathrm{~S}$ & 600 & 1 & 600 & 21.9067 & 0.0003 & \\
$\mathrm{I}_{\mathrm{M}} \mathrm{I}_{\mathrm{P}}$ & 56.25 & 1 & 56.25 & 2.05375 & 0.1723 & \\
$\mathrm{I}_{\mathrm{M}} \mathrm{I}_{\mathrm{F}}$ & 90.25 & 1 & 90.25 & 3.29513 & 0.0895 & \\
$\mathrm{I}_{\mathrm{M}} \mathrm{S}$ & 144 & 1 & 144 & 5.25761 & 0.0367 & \\
$\mathrm{I}_{\mathrm{P}}$ & 156.25 & 1 & 156.25 & 5.70487 & 0.0305 & \\
$\mathrm{I}_{\mathrm{P}} \mathrm{S}$ & 16 & 1 & 16 & 0.58418 & 0.4565 & \\
$\mathrm{I}_{\mathrm{F}} \mathrm{S}$ & 49 & 1 & 49 & 1.78905 & 0.2010 & \\
$\mathrm{I}_{\mathrm{M}}^{2}$ & 1491.86 & 1 & 1491.86 & 54.4694 & $<0.0001$ & \\
$\mathrm{I}_{\mathrm{P}}^{2}$ & 3169.71 & 1 & 3169.71 & 115.73 & $<0.0001$ & \\
$\mathrm{I}_{\mathrm{F}}^{2}$ & 1981.71 & 1 & 1981.71 & 72.3547 & $<0.0001$ & \\
$\mathrm{~S}^{2}$ & 1542.86 & 1 & 1542.86 & 56.3315 & $<0.0001$ & \\
Lack of Fit & 343.5 & 10 & 34.35 & 2.55074 & 0.1565 & Not significant \\
\hline
\end{tabular}

Table 8 Validation of optimization procedures

\begin{tabular}{|c|c|c|c|c|c|c|c|c|c|c|}
\hline \multirow[t]{2}{*}{ Expt. no. } & \multirow[t]{2}{*}{$\begin{array}{l}\text { Peak cur- } \\
\text { rent }(A)\end{array}$} & \multirow[t]{2}{*}{$\begin{array}{l}\text { Inter-pulse } \\
\text { current (A) }\end{array}$} & \multirow[t]{2}{*}{$\begin{array}{l}\text { inter-pulse } \\
\text { frequency (a) }\end{array}$} & \multirow{2}{*}{$\begin{array}{l}\text { Welding } \\
\text { speed (mm/ } \\
\text { min) }\end{array}$} & \multicolumn{2}{|c|}{$\begin{array}{l}\text { Fusion zone grain } \\
\text { size }(\mu \mathrm{m})\end{array}$} & \multirow[t]{2}{*}{ Error (\%) } & \multicolumn{2}{|c|}{$\begin{array}{l}\text { Fusion zone hardness } \\
(\mathrm{Hv})\end{array}$} & \multirow[t]{2}{*}{ Error (\%) } \\
\hline & & & & & Actual & Predicted & & Actual & Predicted & \\
\hline 1 & 52 & 30 & 12 & 60 & 271 & 268 & 1.11 & 417 & 413 & 0.96 \\
\hline 2 & 48 & 35 & 12 & 60 & 255 & 259 & -1.54 & 410 & 417 & -1.67 \\
\hline 3 & 45 & 30 & 10 & 65 & 301 & 299 & 0.66 & 404 & 401 & 0.74 \\
\hline 4 & 50 & 30 & 12 & 65 & 265 & 270 & -1.85 & 424 & 418 & 1.43 \\
\hline
\end{tabular}

Fig. 4 Relationship between fusion zone hardness and fusion zone grain size

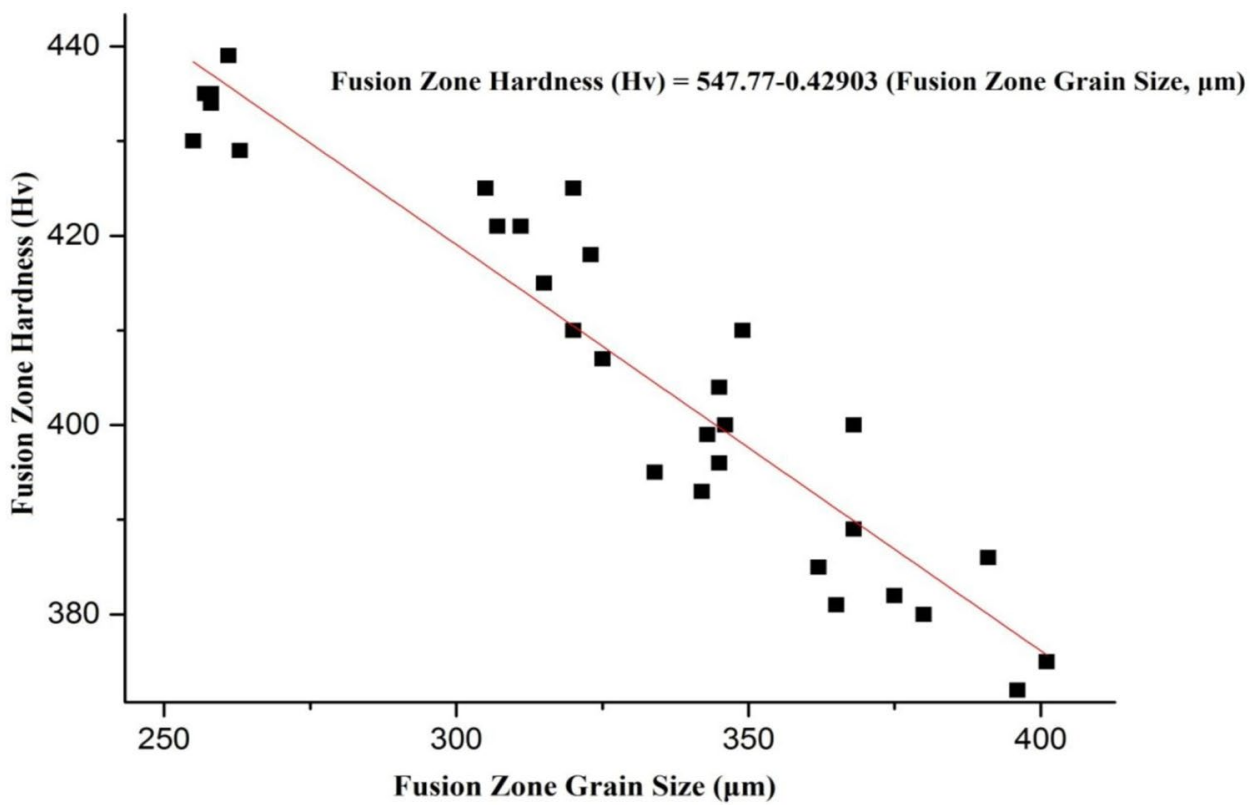

SN Applied Sciences 
fusion zone grain size. The above equation shows $\mathrm{R} 2$ is $96.2 \%$ as a coefficient of determination. The $\mathrm{R} 2$ in regression equation will provides an information about the goodness of the fit. The derived equation can be appropriated to determine the value of $\mathrm{FZH}$ for a given grain size.

\section{Optimization of GTCA welding parameters}

The empirical relationship was developed with help of $R S M$, via taking ' $X$ ' and ' $Y$ ' axis as a parameters and ' $Z$ ' axis as responses. The response surface represents the minimum toward maximum series of responses and shows the apex precisely which represents the optimum solution. In Fig. 5, the apex of response surface was executed by the optimum FZH and FZG of GTCA welded Ti-6Al-4V alloy. The spherical mound shape is illustrated on contour plot and the area of optimal feature settings is displayed with responses through independence factors. Response surface analysis initiate the contour plots with software, the outline of surface can be distinguished with help of rational accuracy which is positioned in optimum. The optimal parameters are shown in Figs. 5 and 6 with an arrow mark. Spherical shape contours are indicative of less interaction between parameters. However, elliptical shape contour are indicate of high interaction between parameters.

\section{Analysis of response graphs and contour plots}

Prior to optimization, it is necessary to illuminate the influence of GTCAW parameters on FZG and FZH. For this purpose, 3D contour plot and response graphs are constructed (see Figs. 5, 6).

Figures $5 \mathrm{a}$ and $6 \mathrm{a}$ illustrate the $3 \mathrm{D}$ response plots of FZG and FZH acquired from the model, considering as an inter-pulse frequency of $12 \mathrm{kHz}$ and peak current of $50 \mathrm{~A}$.

$3 \mathrm{D}$ response plot clearly identify that when increasing inter-pulse frequency to $12 \mathrm{kHz}$, the FZG is finer. The coarser grains are formed at lower inter-pulse frequency, due to less rigorous stirring action of arc in weld pool [24]. Increasing the inter-pulse frequency beyond $12 \mathrm{kHz}$ causes violent and more agitation of the arc in molten weld pool promotes finer grain as well as acicular alpha martensite $\left(a^{\prime}\right)$ structure, so FZH also higher in that region [11]. Hence, acicular alpha martensite $\left(a^{\prime}\right)$ are maximum in optimum inter-pulse frequencies. In this study, an optimum interpulse frequency is to be determined as $12 \mathrm{kHz}$.
Figures $5 c$ and $6 c$ demonstrate the 3D response graph of FZG and $\mathrm{FZH}$ acquired from the model, pretending a welding speed and peak current. From the 3D response graph, it is known that the FZG of joint welded at a $60 \mathrm{~mm} /$ min is finer and FZH of the joints is maximum. The acicular alpha $\left(a^{\prime}\right)$ martensites were bundled in the $F Z$ and this may be accountable for higher hardness of these joints. The lower welding speed yields high heat input in the FZ, which considerably produce coarser grains as well as basket weave structure and reduces the hardness [6]. While increasing the welding speed, the heat input lowers and this causes increase in hardness and the formation of fine grains [14]. Subsequently with high welding speed (above $55-60 \mathrm{~mm} / \mathrm{min}$ ) better quality GTCAW joints are obtained. Few additional joints were produced just beyond the parameters for confirming the rationality of the optimization techniques. Table 8 represent the validation results. An optimization procedures are realistic in this study are concluded from the results.

Figure 7 shows BM optical micrograph (OM) and scanning electron micrographs (SEM) and FZ of the joints fabricated with the optimized parameter $\left(I_{M}=50 A, I_{P}=30\right.$ $A, I_{F}=12 \mathrm{kHz}$ and $S=60 \mathrm{~mm} / \mathrm{min}$ ). The formation of finer grains as well as acicular alpha $\left(a^{\prime}\right)$ martensite in fusion zone is main reasons for higher hardness and minimum fusion zone grain size in these joints $[7,8]$.

\section{Conclusions}

1. Empirical relations were established to assess the fusion zone grains (FZG) and fusion zone hardness (FZH) of Ti-6Al-4V alloy joints.

2. From ANOVA test results, it is found that the interpulse frequency is highly significant GTCAW parameter $(F=222.87)$ and delta current is less significant parameter $(F=68.17)$.

3. Minimum FZG of $253 \mu \mathrm{m}$ and maximum FZH of $439 \mathrm{Hv}$ were attained under the welding conditions $\left(I_{M}=50\right.$ $A, I_{P}=30 \mathrm{~A}, I_{F}=12 \mathrm{kHz}$ and $S=60 \mathrm{~mm} / \mathrm{min}$ ). These set of welding parameters are identified as an optimum GTCAW parameters to attain minimum FZG and maximum FZH with full penetration in $1.2 \mathrm{~mm}$ thin sheets of Ti-6Al-4V alloy employed in aero-engine applications.

4. An empirical relationship was developed relating FZG and $\mathrm{FZH}$ and this relationship can be effectively used to predict FZG from FZH. 
(a)

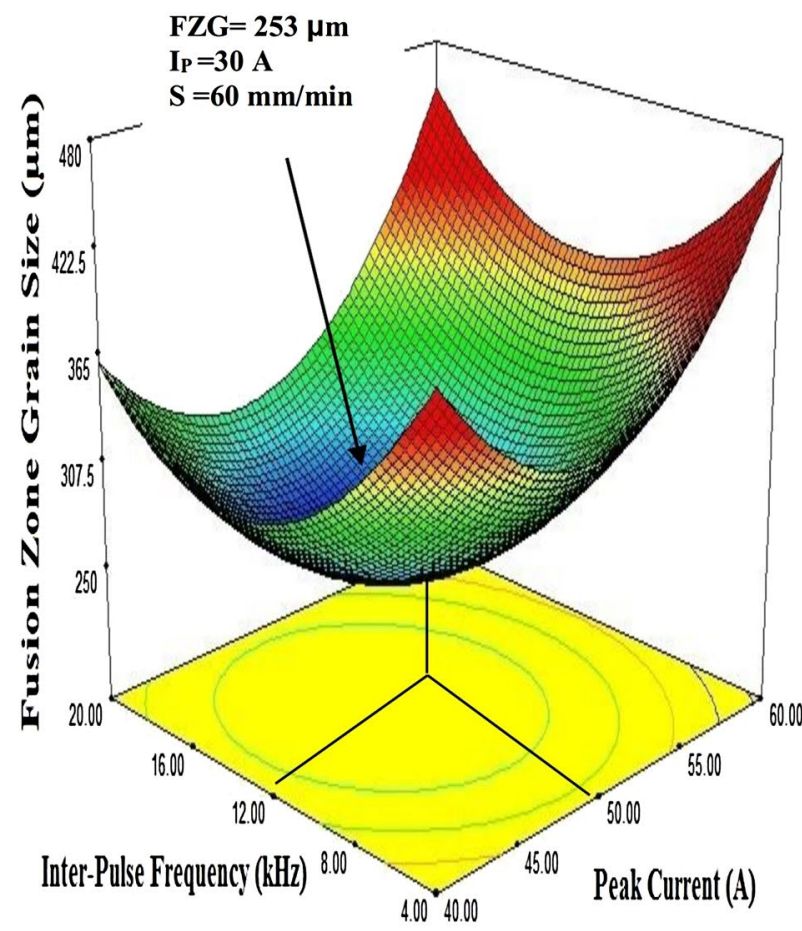

(c)

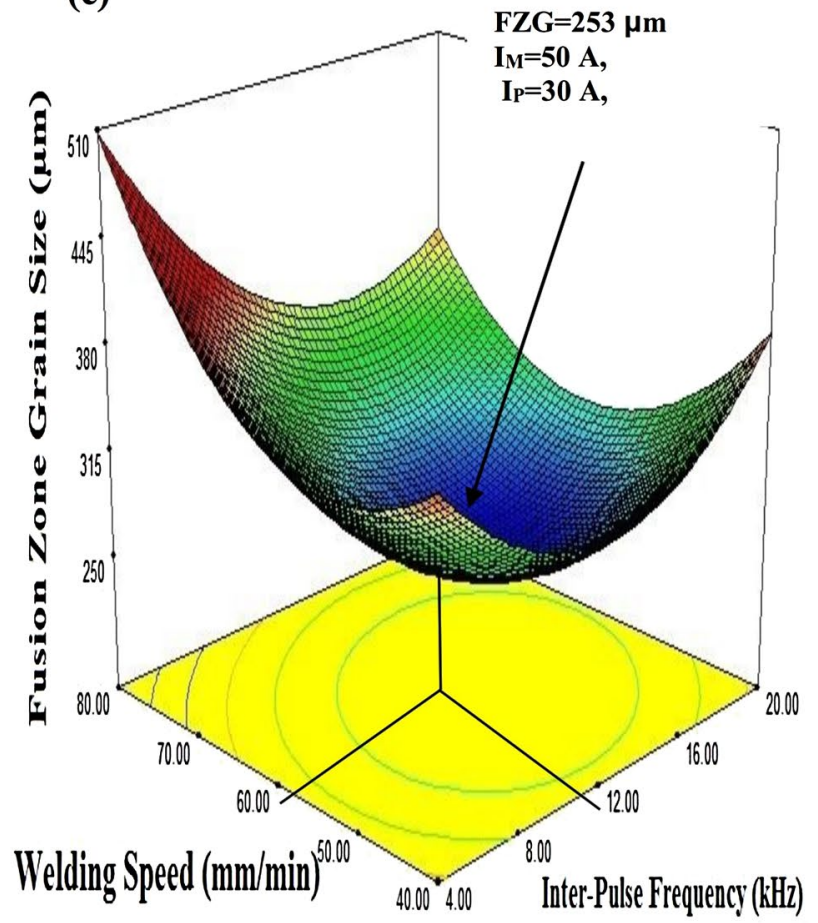

(b)

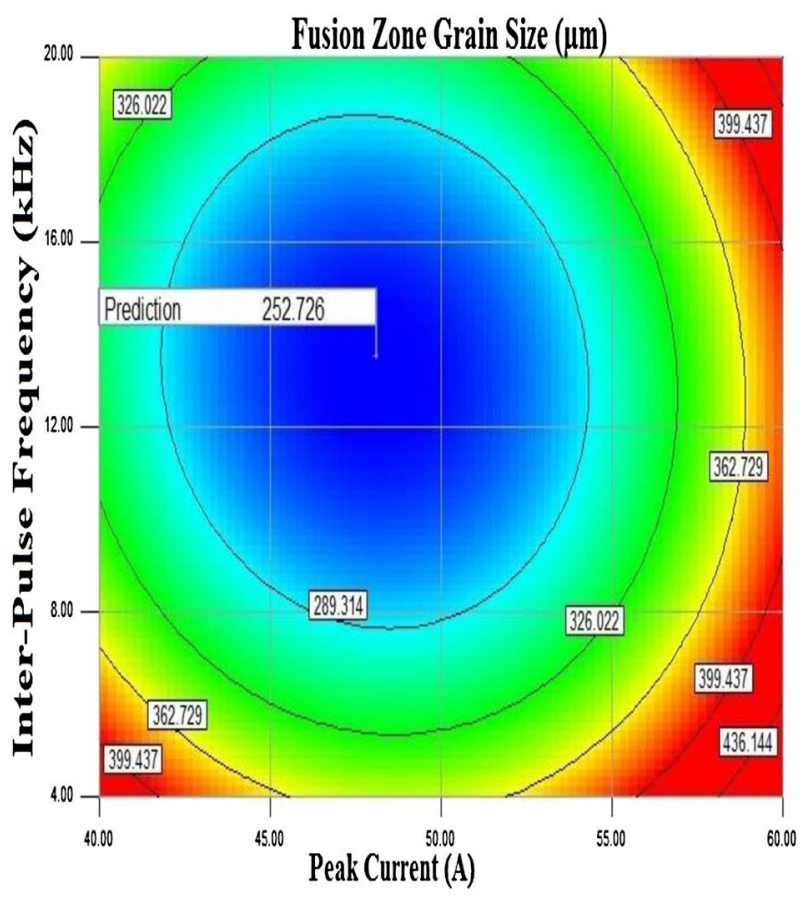

(d)

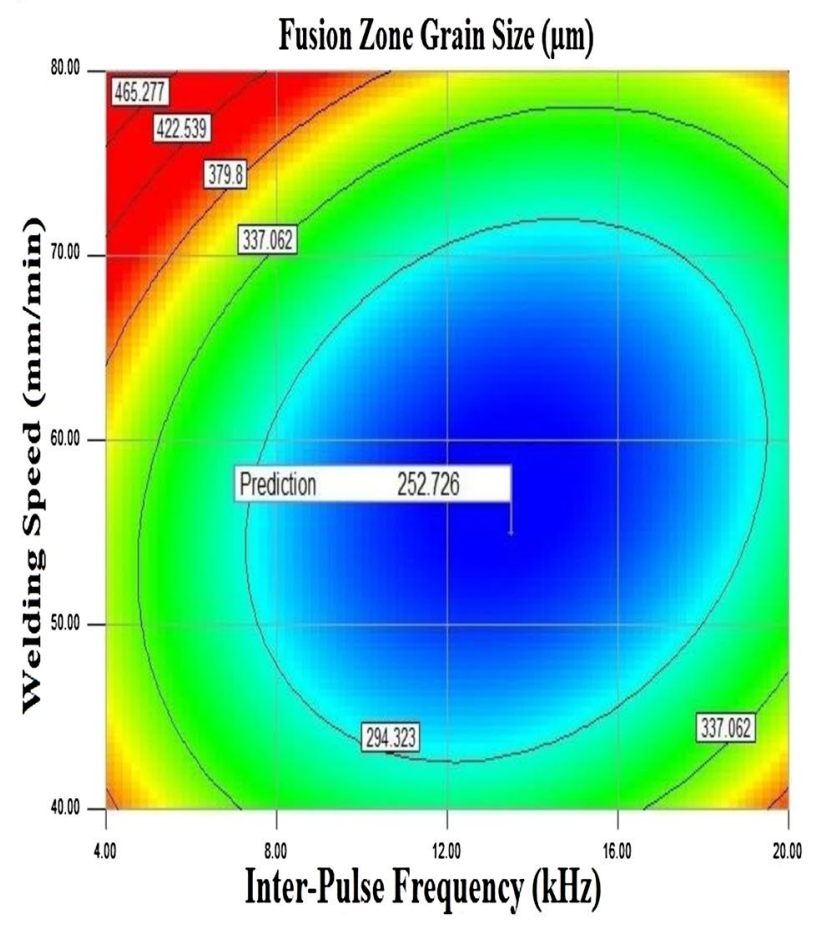

Fig. 5 Response graph and contour plots for fusion zone grain size 


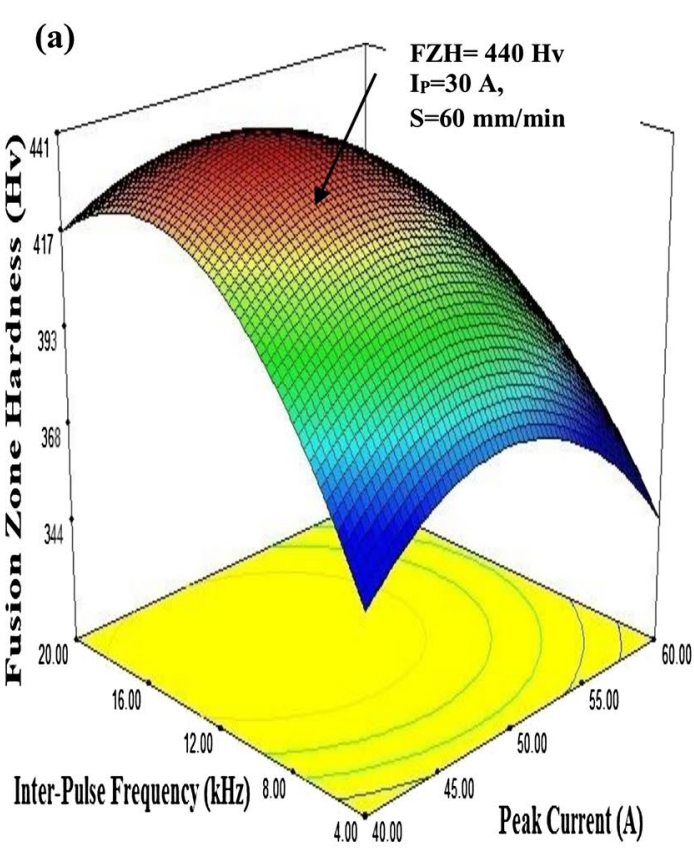

(b)
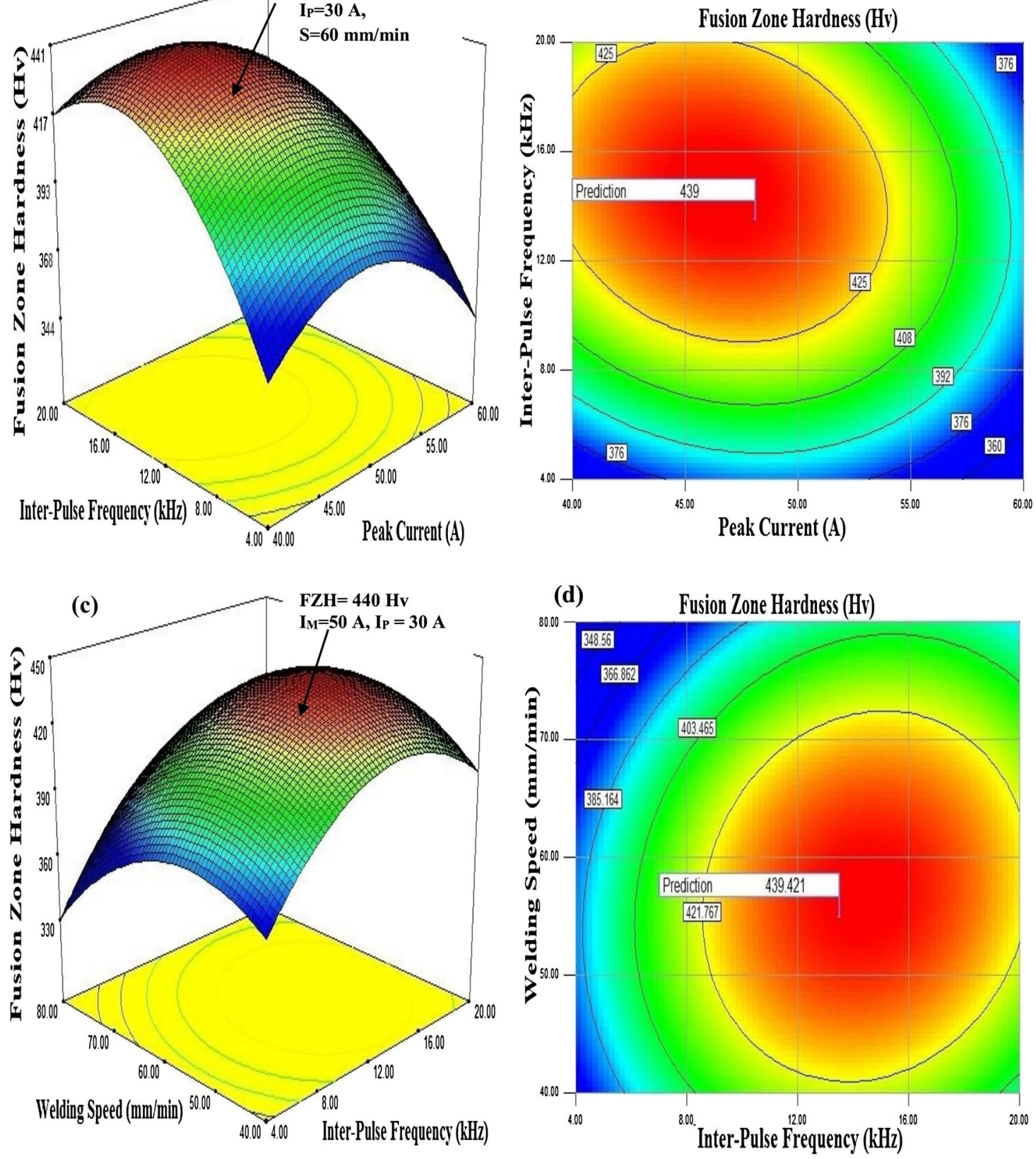

Fig. 6 Response graph and contour plots for fusion zone hardness 


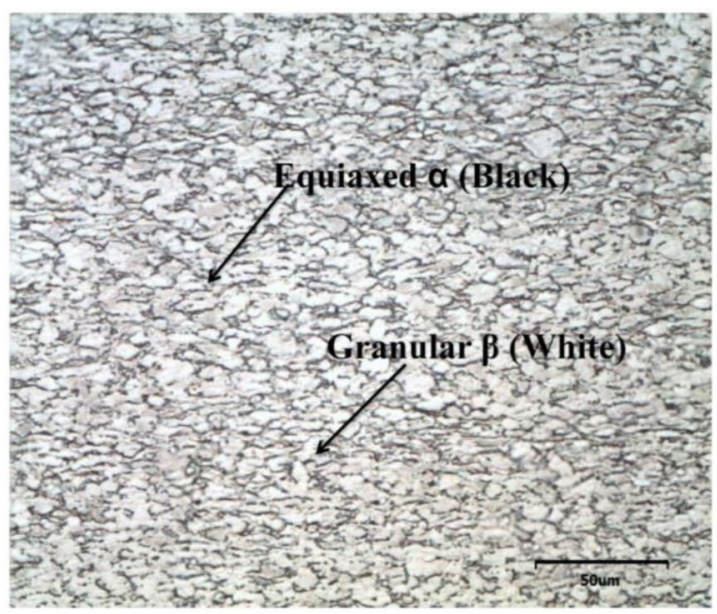

(a)
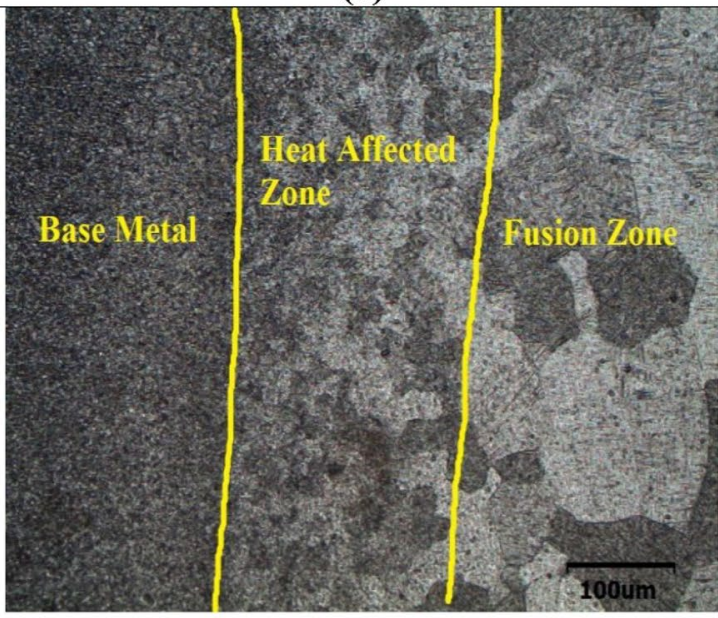

(c)

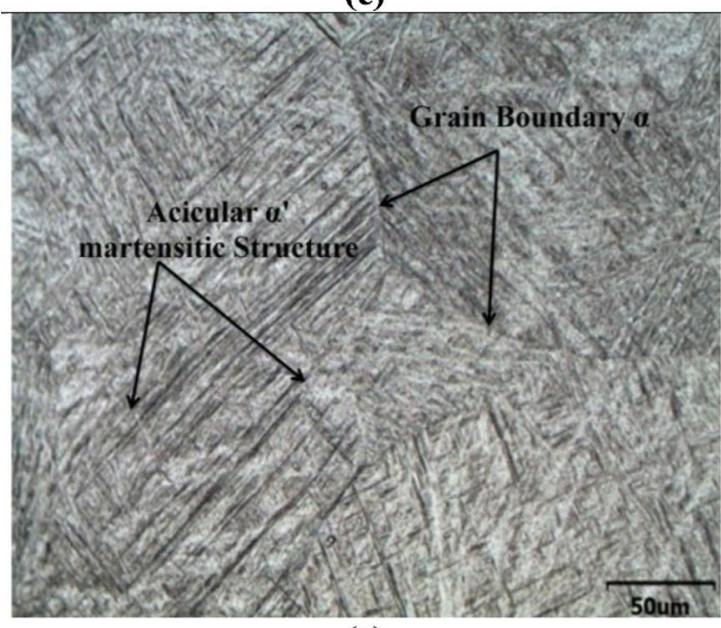

(e)

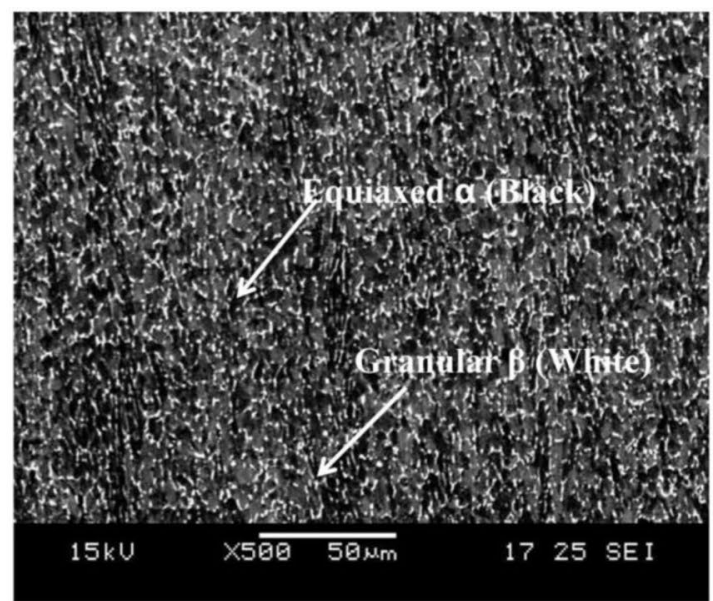

(b)

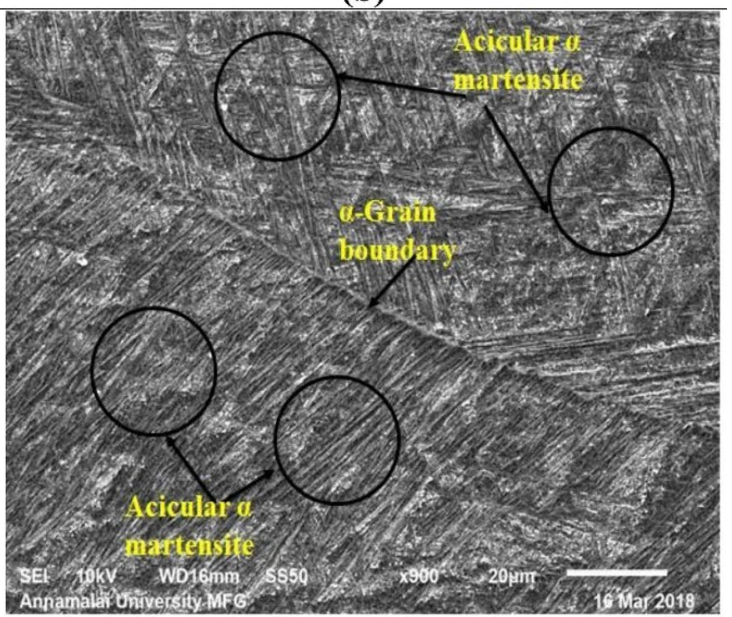

(d)

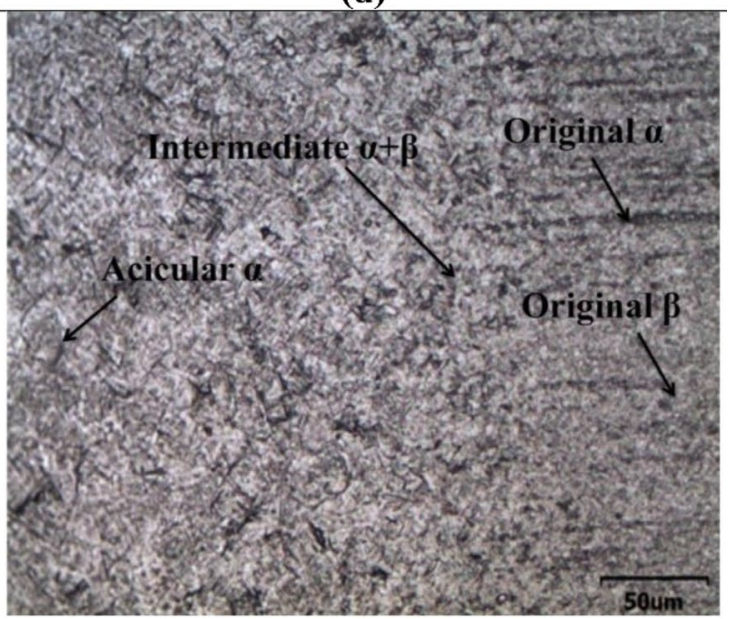

(f)

Fig. 7 Microstructural features of optimized joint: a optical microstructure of base metal. b SEM of base metal. c Transition zone (OM). $\mathbf{d}$ Fusion zone (SEM). e Fusion zone (OM). $\mathbf{f}$ Heat affected zone (OM)

Acknowledgements The authors wish to thank Gas Turbine Research and Establishment (GTRE), Bangalore, for the financial support to carry out this investigation through a R\&D Project No. GTRE/GATET/ CS20/1415/071/15/001 under Gas Turbine Enabling Technology
(GATET) Initiative. The authors also wish to record their sincere thanks to The Director, GTRE, Bangalore for providing base metal to carry out this investigation. 


\section{Compliance with ethical standards}

Conflict of interest The authors declare that they have no conflict of interest.

\section{References}

1. Peters $M$, Kumpfert J, Ward CH, Leyens C (2003) Titanium alloys for aerospace applications. Adv Eng Mater 5:419-427

2. Wang SH, Wei MD (2004) Tensile properties of gas tungsten arc weldments in commercially pure titanium, Ti-6Al-4V and Ti-15V-3Al-3Sn-3Cr alloys at different strain rates. Sci Technol Weld Jt 9:415-422

3. Zhou W, Chew KG (2003) Effect of welding on impact toughness of butt-joints in a titanium alloy. Mater Sci Eng A 347:180-185

4. Cao X, Jahazi M (2009) Effect of welding speed on butt joint quality of Ti-6Al-4V alloy welded using a high-power Nd: YAG laser. Opt Lasers Eng 47:1231-1241

5. Balasubramanian M, Jayabalan V, Balasubramanian V (2008) Effect of microstructure on impact toughness of pulsed current GTA welded $a-\beta$ titanium alloy. Mater Lett 62(6-7):1102-1106

6. Ahmed T, Rack HJ (1998) Phase transformations during cooling in $\alpha+\beta$ titanium alloys. Mater Sci Eng A 243(1):206-211

7. Sundaresan S, Janaki Ram GD, Madhusudhan Reddy G (1999) Microstructural refinement of weld fusion zones in a- $\beta$ titanium alloys using pulsed current welding. Mater Sci Eng $A$ 262:88-100

8. Kishore Babu N, Ganesh Sundara Raman S, Mythili R, Saroja $S$ (2006) Influence of current pulsing on microstructure and mechanical properties of Ti-6AI-4VTIG weldments. Sci Technol Weld Jt 11:442-447

9. Yunlian Q, Ju D, Quan H, Liying Z (2000) Electron beam welding, laser beam welding and gas tungsten arc welding of titanium sheet. Mater Sci Eng A 280:177-181

10. Balasubramanian V, Jayabalan V, Balasubramanian M (2008) Effect of current pulsing on tensile properties of titanium alloy. Mater Des 29(7):1459-1466

11. Xiao-long L-JZ, Liu J, Zhang J-X (2013) A Comparative study of pulsed Nd:YAG laser welding and TIG welding of thin Ti-6AI-4V titanium alloy plate. Mater Sci Eng A 539:14-21

12. Meshram SD, Mohandas T (2010) A comparative evaluation of friction and electron beam welds of near-a titanium alloy. Mater Des 31:2245-2252

13. Saresh N, Pillai MG, Mathew J (2007) Investigations into the effects of electron beam welding on thick Ti-6Al-4V titanium alloy. J Mater Process Technol 192:192-193
14. Balasubramanian TS, Balakrishnan M, Balasubramanian V, Manickam MM (2011) Influence of welding processes on microstructure, tensile and impact properties of Ti-6Al-4V alloy joints. Trans Nonferrous Met Soc China 21(6):1253-1262

15. Gao XL, Zhang LJ, Liu J, Zhang JX (2014) Comparison of tensile damage evolution in Ti-6A1-4V joints between laser beam welding and gas tungsten arc welding. J Mater Eng Perform 23:4316-4327

16. Leary R, Merson E, Birmingham K, David H, Brydson R (2010) Microstructural and microtextural analysis of InterPulse GTCAW welds in Cp-Ti and Ti-6Al-4V. Mater Sci Eng A 527:7694-7705

17. Vaithiyanathan V, Balasubramanian V, Malarvizhi S, Petlay V, Verma S (2018) Identification of optimized gas tungsten constricted arc welding parameters to attain minimum fusion zone area in $\mathrm{Ti}-6 \mathrm{Al}-4 \mathrm{~V}$ alloy sheets used in aero engine components. J Adv Microsc Res 13:354-362

18. Leary R, Merson E, Brydson R (2010) Microtextures and grain boundary misorientation distributions in controlled heat input titanium alloy fusion welds. J Phys Conf Ser 241:012103

19. Tarang YS, Tsai HL, Yeh SS (1999) Optimization and classification of weld quality in TIG welding. Int J Mach Tools Manuf 39(9):1427-1438

20. Ravisankar V, Balasubramanian V (2006) Optimising pulsed current TIG welding parameters to refine the fusion zone. Sci Technol Weld Jt 1(11):57-60

21. Usman Al, Aziz AA, Sodipo BK (2019) Application of central composite design for optimization of biosynthesized gold nanoparticles via sonochemical method. SN Appl Sci 1:403

22. Balasubramanian M, Jayabalan V, Balasubramanian V (2009) Prediction and optimization of pulsed current gas tungsten arc welding process parameters to obtain sound weld pool geometry in titanium alloy using lexicographic method. J Mater Eng Perform 18(7):871-877

23. Balasubramanian M, Jayabalan V, Balasubramanian V (2008) Developing mathematical models to predict grain size and hardness of argon tungsten pulse current arc welded titanium alloy. J Mater Process Technol 196(1-3):222-229

24. Padmanban G, Balasubramanian V (2011) Optimization of pulsed current gas tungsten arc welding process parameters to attain maximum tensile strength in AZ31B magnesium alloy. Trans Nonferr Met Soc China 21:467-476

25. Subravel V, Padmanaban G, Balasubramanian V (2014) Optimizing the pulsed current GTAW process parameters to attain maximum tensile strength using RSM. Indian Weld J 47:43-56

Publisher's Note Springer Nature remains neutral with regard to jurisdictional claims in published maps and institutional affiliations. 